\title{
Indications and the Outcome of the Mammography at Douala General Hospital (Cameroon)
}

\author{
Mathurin Neossi Guena ${ }^{1,2^{*}}$, Natacha Doudou Raïssa1, Emmanuela Manka'a Wankie ${ }^{3}$, \\ Louisette Guedong Megnikengni ${ }^{1}$, Narcisse Nwedjiwe Nana ${ }^{3}$, Souadatou Inna ${ }^{1}$, \\ Frantz Cedric Nyatte ${ }^{1}$, Celestine Nguemgne ${ }^{3}$, Wanko Woguep Laure Vanina ${ }^{3}$, \\ Joseph Fotsin Gonsu ${ }^{4}$
}

\footnotetext{
${ }^{1}$ Department of Biomedical Sciences, Faculty of Science, The University of Ngaoundere, Ngaoundere, Cameroon

${ }^{2}$ Medical Imaging Center of Ngaoundere Regional Hospital, Ngaoundere, Cameroon

${ }^{3}$ Medical Imaging Department of Douala General Hospital, Douala, Cameroon

${ }^{4}$ Radiology and Radiotherapy Department, Faculty of Medicine and Biomedical Sciences, The Universityof Yaounde I, Yaounde, Cameroon
}

Email: *13508371062@163.com

How to cite this paper: Guena, M.N., Raïssa, N.D., Wankie, E.M., Megnikengni, L.G., Nana, N.N., Inna, S., Nyatte, F.C., Nguemgne, C., Vanina, W.W.L. and Gonsu, J.F. (2018) Indications and the Outcome of the Mammography at Douala General Hospital (Cameroon). Open Journal of Radiology, 8, 99-108.

https://doi.org/10.4236/ojrad.2018.82012

Received: May 12, 2018

Accepted: June 24, 2018

Published: June 27, 2018

Copyright $\odot 2018$ by authors and Scientific Research Publishing Inc. This work is licensed under the Creative Commons Attribution International License (CC BY 4.0).

http://creativecommons.org/licenses/by/4.0/ c) (i) Open Access

\begin{abstract}
Background: Recent reports indicate that the use of mammography in breast screening plays a major role in reducing breast cancer-related deaths. It helps to improve quality of care and patient information. However, in Cameroon, there are no organized general breast screening programs which give women the opportunity to regularly screen their breasts, except for the few who take their own initiative for breast screening. Purpose: This study aimed to list indications and results of mammography and/or breast ultrasounds at Douala General Hospital in order to determine the proportion of routine mammographic screening. Method: This descriptive cross-sectional study was carried out at Douala General Hospital using pre-established data sheets. The study recruited all patients who met the selection criteria and reported to the radiology and medical imaging department for breast screening using physical examinations, mammography and/or ultrasounds. Results: The study recruited 372 patients, $96.8 \%$ of whom were between 40 to 50 years old. The reasons given for the medical consultation were systematic screening (33.01\%); pain $(27.18 \%)$ and lumps (25.24\%). Breast examination by inspection was normal in $87.1 \%$ of women, and by palpation in $66.7 \%$. Mammography revealed nodular opacities (18.3\%), spiculated images (4.3\%) and micro calcifications (3.2\%), while ultrasound identified fibroadenomas (16.48\%) and cysts (6.18\%). Suspicious lesions (ACR 4 and 5) were discovered in 7.6\% of cases by mammography and $8.51 \%$ of cases by ultrasound. The results indicated that
\end{abstract}


there was no significant association between the use of clinical examination and mammography $(\mathrm{p}=0.754)$. The use of clinical examination alone for breast screening may not be sufficient. Conclusion: Our findings indicate that in Cemaroon, the routine screening mammography accounts for less than one-third $(33.1 \%)$ of all indications. Benign lesions were most common, however $7.6 \%$ and $8.51 \%$ of suspicious malignant lesions were observed using mammography and ultrasound respectively.

\section{Keywords}

Mammography, Ultrasound, Breast Cancer Screening, Benign and Malignant Lesions

\section{Introduction}

Breast cancer is a major cause for concern for the medical staff as well as for the patients. It represents a little bit more than one-third of all cancers. It is reported to be the leading cause of cancer-related deaths among women with an estimated 11,500 deaths per year in France [1].

In Cameroon, it is reported that breast cancer is the most common cancer (48.12\%) among women [2] [3]. In low income countries, many of these cancer cases are detected at advanced stages due to lack of access to diagnostic equipment (medical imaging technologies) and routine medical consultations [4] [5]. Mammography, ultrasonography and Magnetic Resonance Imaging are the most common imaging modalities used for breast screening. Mammography is a low-dose-x-ray imaging modality used to create detailed images of the breast. It is the first line method for detecting breast cancer early when treatment is most effective. Indications for mammography can be put in two main groups. The first group is screening mammography which is performed on asymptomatic women and the second is diagnostic mammography mostly performed on symptomatic women [6].

It is stated that early diagnosis improves prognosis. Breast screening using mammography is reported to reduce breast cancer-related deaths by $15 \%$ among women [7] [8]. Regular breast cancer screening leads to early detection of a great number of subclinical breast lesions that might require further investigations in order to specify their nature and more efficient treatment. There are two ways of organizing screening mammography. The first way is by communal screening which targets the general population. The second is by individual voluntary screening among women who are genetically susceptible or present high risks factors [9]. To the best of our knowledge, there has not been any regular organized communal breast screening program using mammography in Cameroon. However recently, public health authorities have given more importance to individual voluntary screening either by auto palpation or mammography or both. The aim of using mammography screening is to detect any abnormality in the 
breast by the analysis of images which could reveal precancerous lesions and small-size cancers. On the contrary, the use of palpation and other forms of physical examination in breasts screening, usually only detect advanced stage cancer and treatment is therefore delayed [9]. To the best of our knowledge no publication has been made in sub-Saharan African on the indications and results of mammography. We therefore conducted this study at the Douala General Hospital with a view to identify the reasons why women presented for mammography examination and the results obtained, with the end goal being to determine the place of individual routine screening mammography in this health facility.

\section{Material and Method}

This cross-sectional descriptive study was carried out at Douala General Hospital for one year, from April 2016 to March 2017. Sampling was consecutive and exhaustive non-probabilistic. The study included all patients who came to the radiology and medical imaging department for breast imaging and freely consented to participate.

Each patient recruited for this study had to go through a clinical examination including medical history, inspection and palpation; followed by a mammogram with craniocaudal and medial-lateral oblique images. The use of ultrasound assessment of the breast was optional, depending on the age of the patient. Ultrasound is more useful for patients who are relatively young and/or have dense breasts. The images were read and described by the radiologist. The lesions were grouped according to the ACR's BI-RADS classification, and the data collected on a pre-set data sheet. Patient confidentiality was paramount. Microsoft Office Excel 2013 and Sphinx version 5.1.0.6 were used for data analysis. Chi-square test was used with a precision threshold $\mathrm{p}=0.05$.

\section{Results}

Three hundred and seventy-two (372) patients aged between 18 and 83 years old were enrolled in this study; $360(96.80 \%)$ women and 12 (3.2\%) men, with a sex ratio $\mathrm{W} / \mathrm{M}$ of 30 . The modal age group was 40 to 50 years old representing $33.33 \%$ (Figure 1). The principal indications for mammography were : routine breast screening (33.01\%), breast pain (27.18\%), and breast lumps (25.24\%) (Table 1). Clinical examination by inspection revealed that $87.1 \%$ of the study population had normal breast, $5.4 \%$ had breast lumps and $4.3 \%$ had breast scars (Table 2). Palpation revealed that $66.7 \%$ had normal breast and $26.9 \%$ had breast lumps (Table 3 ).

Findings reported on mammograms included (Table 4): nodular opacities (18.3\%), spiculated masses (4.3\%), micro calcifications (3.2\%) and normal breast (58.1\%). Complementary ultrasound examination (Table 5) helped to identify and better characterise certain lesions such as fibroadenomas (32\%) and cysts (12\%). Suspected malignancies (ACR 4) accounted for $4.30 \%$ of mammography 
images and $2.13 \%$ on ultrasound images. Features strongly suggestive of cancer (ACR 5) were reported for $3.30 \%$ of mammograms and $6.38 \%$ of ultrasounds (Figure 2 and Figure 3).

The chi-square test shows that there was no statistically significant association between clinical findings and mammography $(\mathrm{p}=0.754)$. However, there was a strong association between ACR classifications using mammographic and ultrasound $(\mathrm{p}=0.01)($ Table 6$)$

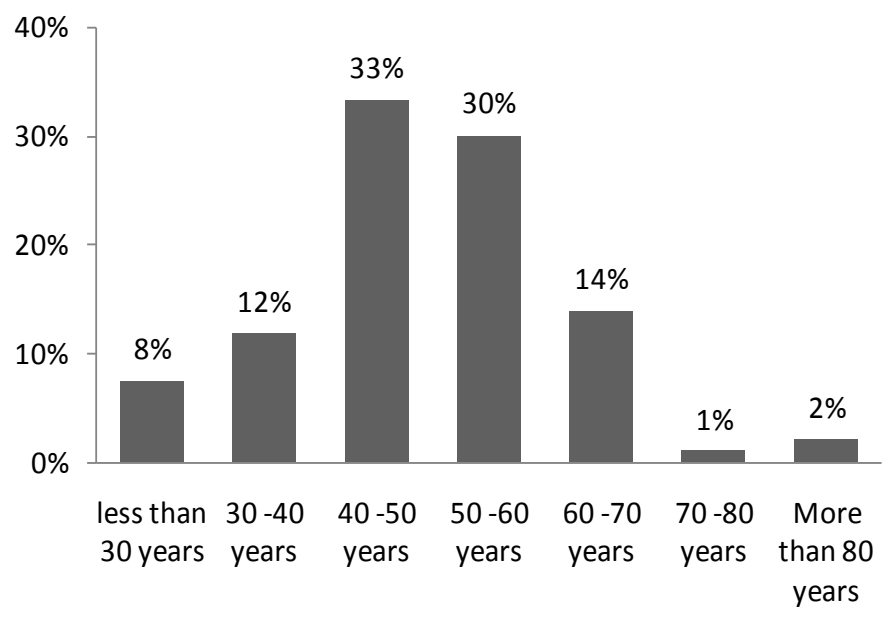

Figure 1. Distribution of patients by age group.

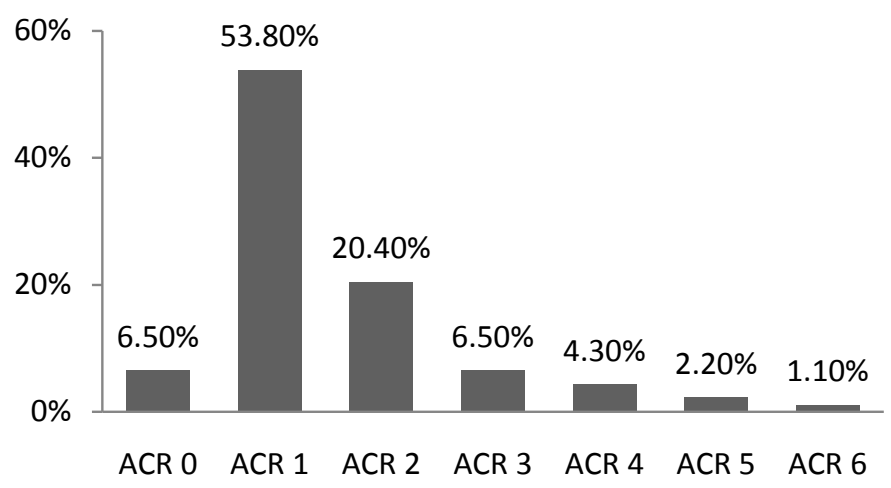

Figure 2. ACR classification of lesions detected on mammography images.

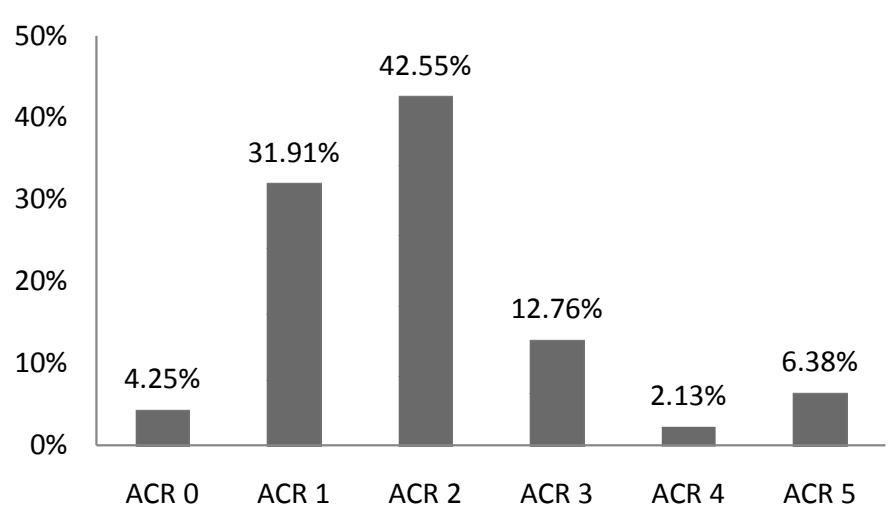

Figure 3. ACR classification of lesions reported on breast ultrasound. 
Table 1. Distribution of consultation motives.

\begin{tabular}{ccc}
\hline consultation motives & $n$ & frequencies \\
\hline Routine Screening & 136 & $33.01 \%$ \\
lumps & 104 & $25.24 \%$ \\
Pain & 112 & $27.18 \%$ \\
Tingling & 28 & $6.80 \%$ \\
Nipple discharge & 16 & $3.88 \%$ \\
Mastitis & 8 & $1.94 \%$ \\
control & 8 & $1.94 \%$ \\
Total & 412 & $100 \%$ \\
\hline
\end{tabular}

Table 2. Signs observed at the inspection.

\begin{tabular}{ccc}
\hline Inspection & $n$. & Frequencies \\
\hline Normal & 324 & $87.1 \%$ \\
lumps & 20 & $5.4 \%$ \\
scars & 16 & $4.3 \%$ \\
mastitis & 8 & $2.2 \%$ \\
Nipple discharge & 4 & $1.1 \%$ \\
Total & 372 & $100 \%$ \\
\hline
\end{tabular}

Table 3. Information revealed by palpation.

\begin{tabular}{ccc}
\hline Palpation & $n$ & Frequencies \\
\hline Normal & 248 & $66.7 \%$ \\
lumps & 100 & $26.9 \%$ \\
Nipple discharge & 20 & $5.4 \%$ \\
Pain & 4 & $1.1 \%$ \\
Total & 372 & $100 \%$ \\
\hline
\end{tabular}

Table 4. Lesions features on mammography.

\begin{tabular}{ccc}
\hline Features & $n$ & Frequencies \\
\hline Normal & 220 & $59.2 \%$ \\
Nodular opacities & 68 & $18.3 \%$ \\
spiculated masses & 16 & $4.3 \%$ \\
Micro calcifications & 12 & $3.2 \%$ \\
Macrocalcifications & 12 & $3.2 \%$ \\
Lymph nodes & 12 & $3.2 \%$ \\
Others & 12 & $3.2 \%$ \\
No anwser & 20 & $5.4 \%$ \\
Total obs. & 372 & $100 \%$ \\
\hline
\end{tabular}

No answer*: patients who performed only breasts ultrasounds examination. 
Table 5. Lesions reported on breast ultrasound.

\begin{tabular}{ccc}
\hline Lesions features & $n$ & Frequencies \\
\hline Fibroadenomas & 64 & $32 \%$ \\
Normal & 64 & $32 \%$ \\
cysts & 24 & $12 \%$ \\
Axillary lymph nodes & 8 & $4 \%$ \\
Dilated breast ducts & 8 & $4 \%$ \\
Abnormal intradermal structures & 8 & $4 \%$ \\
Gynecomastia & 4 & $2 \%$ \\
Other suspicious abnormalities & 20 & $10 \%$ \\
Total & 200 & $100 \%$ \\
\hline
\end{tabular}

Table 6. Correlation between mammography and ultrasound findings and classification. There is a strong correlation between mammography and ultrasound $(\mathrm{p}=0.01)$.

\begin{tabular}{|c|c|c|c|c|c|c|c|c|}
\hline ACR ultrasounds & \multirow{2}{*}{$A C R 0$} & \multirow{2}{*}{$A C R 1$} & \multirow{2}{*}{$A C R 2$} & \multirow{2}{*}{$A C R 3$} & \multirow{2}{*}{$A C R 4$} & \multirow{2}{*}{$A C R 5$} & \multirow{2}{*}{$N A^{*}$} & \multirow{2}{*}{ TOTAL } \\
\hline ACR Mammography & & & & & & & & \\
\hline$A C R 0$ & 4 & 0 & 0 & 4 & 0 & 4 & 12 & 24 \\
\hline$A C R 1$ & 4 & 48 & 24 & 0 & 0 & 0 & 124 & 200 \\
\hline$A C R 2$ & 0 & 8 & 36 & 0 & 0 & 0 & 32 & 76 \\
\hline$A C R 3$ & 0 & 0 & 4 & 16 & 0 & 0 & 4 & 24 \\
\hline$A C R 4$ & 0 & 0 & 0 & 4 & 4 & 0 & 8 & 16 \\
\hline$A C R 5$ & 0 & 0 & 0 & 0 & 0 & 8 & 0 & 8 \\
\hline$A C R 6$ & 0 & 0 & 0 & 0 & 0 & 0 & 4 & 4 \\
\hline No Answer* & 0 & 4 & 16 & 0 & 0 & 0 & 0 & 20 \\
\hline TOTAL & 8 & 60 & 80 & 24 & 4 & 12 & 184 & 372 \\
\hline
\end{tabular}

$\mathrm{NA}^{*}$ : Patients on whom only mammography was performed. No Answer*: Patients on whom only ultrasound was performed.

\section{Discussion}

Recent reports indicate that the rate of breast cancer is increasing in sub-Saharan Africa [10]. In 2012, about 134,000 breast cancer cases were diagnosed with 63,000 breast cancer-related deaths in Africa. Sub-Sahara Africa alone recorded 94,000 breast cancer cases and 48,000 breast cancer-related deaths [11]. This is expected to double in the next 30 years probably due to lack of regular breast cancer screening and awareness among women. Breast cancer screening is one of the major public health concerns [5]. In Cameroon, there are no regular breast screening programs for women, perhaps due to lack of resources. Many women depend on self-breast examination or individual voluntary breast screening at the hospital [2]. It is sometimes based on a doctor's request. This type of request is often limited to a small group of individuals and has a mini- 
mum effect on reducing breast cancer-related deaths when compared to organized free breast screening programs which give many more women the opportunity to undergo breast screening.

Lack of medical diagnostic equipment and qualified personnel in many poor resource countries are some of the major challenges to breast screening [4]. In Cameroun, mammography and ultrasound are the most commonly used diagnostic imaging modalities for breast cancer screening. At the early stage even without obvious symptoms, breast cancer can be detected by mammography. Breast cancer treatment is more efficient at these early stages than when the symptoms become apparent [10]. Randomised trials of breast cancer screening using mammography have been reported to reduce breast cancer-related deaths by at least $15 \%$ [8]. In the USA, there are well organized national breast screening programs for the public. This gives every woman and man the opportunity to regularly undergo breast screening annually or once every two years, using either mammography or more advanced methods for early detection of breast abnormalities [12]. It is also required by law that two independent radiologists meticulously read the images of the mammogram to attest the absence of cancer lesions [9]. A recent swedish study showed that in countries that offered routine screening mammography, there were $29 \%$ fewer deaths from breast cancer over a 16 year period among women who underwent screening, than those that did not [13]. In our study, we realized that $33.01 \%$ of women who presented for a mammography were asymptomatic and $67 \%$ were symptomatic with complaints like pain, nipple discharge or lumps. Although mammography is the most cost-effective approach for breast-cancer screening, our results, however, suggest that few women undergo breast screening mammography in Cameroun perhaps due to lack of organized free breast screening or awareness. Smith R.A. [13], discussed the issue of the age at which women should begin breast screening, and what information can help women and their clinicians inform this decision. On school of thought holds that progress in therapy overlap the benefit of early detection and that the harms associated with screening outweigh the benefits. A second opinion discourages initiation of breast screening until the age of 50. The last school of thought supports initiation of screening at the age of 40 [13]. In this study, we realized the modal age subjects presenting for breast cancer screening was 40 - 60 years representing $66.33 \%$. Similar findings were also reported by Belley and al, and Diakité N. [14] [15]. This is in line with the initiation of breast screening between the ages of 40 to 50 years. This finding also ties with recent recommendations by the American Cancer Society (ACS) in 2015 urging all women to start mammograms at age 45 or 40 [16].

Breast screening by mammography is noted to be $77 \%$ to $95 \%$ sensitive and $94 \%$ to $97 \%$ specific in the detection and identification of breast lesions [17]. The use of mammography in this study contributed in the detection of different types of breast lesions such as nodular opacities (18.3\%), spiculated images (4.3\%) and micro calcifications (3.2\%). We also classified 7.6\% of these lesions 
which as suspicious of malignancy (ACR 4 or 5). The used of complementary ultrasound in this study helped detection and characterisation of lesions that were unnoticed on mammograms from subjects with dense breasts, as fibroadenomas (16.48\%) and cysts (6.18\%). Guegang and al in their study using ultrasound for the breast screening classified $16.5 \%$ of lesions as suspicious of malignancy [14]. However, in our study, we found much less (8.51\%).

Although breast cancer in men is rare and accounts for only about $1 \%$ of all breast cancers [18], 3.2\% of our study population was male. Our findings, therefore suggest that well established organized free breast screening mammography programs in Cameroun may help in early diagnoses of patients with malignant lesions which are generally asymptomatic. It may also help patients with malignant lesions to start their treatments early, improve quality of care and possibly reduce breast-cancer related death.

It has been reported that mammography combined with clinical breast examination slightly improves sensitivity (77\%) [17]. In this study, our results failed to show a significant correlation between the clinical examination and the mammography results $(\mathrm{p}=75.4)$. This shows that the use of clinical examination alone is not sufficient for the detection of breast diseases such as small-size lesions or micro calcifications. Hence the recommendation for the combined clinical examination and mammography for a better outcome in breast screening. Ultrasound is mostly used to complement the evaluation of suspicious lesions detected on mammography and/or clinical examination. It is limited by a number of factors, notably the failure to detect micro calcifications and poor specificity (34\%) [19] [20]. In this study, our results showed a significant association between ACR classifications on mammography and ultrasounds $(\mathrm{p}=0.01)$. A couple of examinations show that the combined use of mammography and ultrasound seemed to be more reliable for detection and characterization of breast lesions among women over 45 years in Cameroon [21].

As limitations: the study concerns a single hospital and cannot give the true level of breast cancer screening by mammography in Cameroon. The pathological anatomy was not performed to determine the true rate of cancer and benign lesions during screening.

\section{Conclusion}

Our study findings indicate that breast diseases in our context are more prevalent among relatively younger women. The most common reasons for performing mammography at the Douala General Hospital are routine screening (33.01\%), pain (27.18\%) and lumps (25.24\%). Mammography revealed lesions suspicious of malignancy in $7.6 \%$ of cases and ultrasound revealed $8.51 \%$ of cases. The chi-squared independence test showed that there was no statistically significant association between clinical examination and mammography. Clinical examination thus proves inadequate for screening for breast pathology hence the importance of introducing mammography for breast cancer screening in our 
country.

\section{Acknowledgements}

We thank the authorities of Douala General Hospital especially the staff of the Department of Radiology and Medical Imaging for their support during this study. We wish to thank Sylvanus Kampo for his contribution in editing this manuscript.

\section{Conflict of Interest}

None.

\section{References}

[1] National Cancer Institute (2011) The Cancer Situation in France in 2010. http://www.e-cancer.fr/

[2] Enow-Orock, G., Mbu, R., Ngowe, N.M., Tabung, F.K., Mboudou, E., Ndom, P., et al. (2006) Gynaecological Cancer Profile in Yaoundé Population Cameroon. Clinics in Mother and Child Health, 3, 437-444.

[3] Edzimbi, A.L. (2008) The Clinical and Histopathological Aspects of Breast Cancer in Cameroonian Women at HGOPY. Thesis of Medicine, FMSB; University de Yaoundé I.

[4] Clegg-Lamptey, J.N. (2017) Epidemiology of Breast Cancer in Africa. OncologyPRO.

http://oncologypro.esmo.org/content/download/102746/1814743/2017-ESMO-Afric a-Epidemiology-of-Breast-Cancer-in-Africa-Joe-Nat+Clegg-Lamptey.pdf

[5] Kantelhardt, E.J. and Frie, K.G. (2016) How Advanced Is Breast Cancer in Africa? The Lancet, 4. http://www.thelancet.com/lancetgh

[6] Pascal, A., Baltzer, T., Panagiotis, K., Maria Adele, M. and Paola, C. (2017) New Diagnostic Tools for Breast Cancer. Memo, 10, 175-180.

https://doi.org/10.1007/s12254-017-0341-5

[7] Shapiro, S., Venet, W., Strax, P., Venet, L. and Roeser, R. (1982) Ten-to Fourteen Year Effect of Screening on Breast Cancer Mortality. Journal of the National Cancer Institute, 69, 349-355.

[8] Nelson, H.D., Tyne, K., Naik, A., Bougatsos, C., Chan, B., Nygren, P. and Humphrey, L. (2009) Screening for Breast Cancer: Systematic Evidence Review Update for the U.S. Preventive Services Task Force. Annals of Internal Medicine, 151, 727-737.

[9] High Authority of Health (2011) Screening for Breast Cancer in France: Identification of High-Risk Women and Screening Modalities. https://www.has-sante.fr/portail/jcms/c_1741170/fr/depistage-du-cancer-du-sein-e n-france-identification-des-femmes-a-haut-risque-et-modalites-de-depistage

[10] Abdulrahman Jnr., G.O. and Rahman, G.A. (2012) Epidemiology of Breast Cancer in Europe and Africa. Journal of Cancer Epidemiology. https://doi.org/10.1155/2012/915610

[11] Ferlay, J., Soerjomataram, I., Ervik, M., et al. International Agency for Research on Cancer. GLOBOCAN 2012 v1.0, Cancer Incidence and Mortality Worldwide: IARCCancerBase No. 11. Globocan.iarc.fr. Retrieved on December 16, 2016.

[12] DeSantis, C.E., Ma, J., Sauer, A.G., Newman, L.A. and Jemal, A. (2017) Breast Can- 
cer Statistics, 2017, Racial Disparity in Mortality by State. CA: A Cancer Journal for Clinicians, 67, 439-448.

[13] Smith, R.A., Kerlikowske, K., Miglioretti, D.L. and Kelager, M. (2012) Mammography Screening for Breast Cancer. The New England Journal of Medicine.

[14] Belley Priso, E., Nguemgne, C., Obenchemti, E. and Mouné, A. (2010) Epidemiological and Clinical Profile of Breast Pathology at Douala General Hospital (Cameroon). Health Sciences and Disease, 11.

[15] Nouhoum, D. (2011) Breast Cancer: Clinical and Therapeutic Aspects in the "A" Surgery Service of the G-Point CHU. African Journal of Cancer.

[16] Thompson, D. (2015) Cancer Society: Mammograms Should Start at 45; Oct. 20. Health Day News. Retrieved on November 23, 2017.

[17] Nelson, H.D., Tyne, K., Naik, A., Bougatsos, C., Chan, B., Nygren, P. and Humphrey, L. (2009) Screening for Breast Cancer: Systematic Evidence Review Update for the U.S. Preventive Services Task Force. Annals of Internal Medicine, 151, 727-W242. https://doi.org/10.7326/0003-4819-151-10-200911170-00009

[18] League against Cancer. All Cancers: Breast Cancer. https://www.ligue-cancer.net/localisation/sein

[19] Erin Newton, V., Marie Catherine, L., Sara Grethlein, J., et al. (2017) Breast Cancer Screening. Medscape. https://emedicine.medscape.com/article/1945498-overview

[20] Guegang, E., Sandjong, T.I., Tebeu, P.M., Temgoua, B.A., Sando, Z. and Moulion, J.R. (2012) Contribution of Ultrasound in Screening and Diagnosis of Breast Cancer: An Experiment from Yaoundé, Cameroon. Clinics in Mother and Child Health, 9.

[21] Guegang, E., Magny, E.T., Wantou, L.G.S., Gonsu, J. and Sando, Z. (2009) Breast Cancer Screening. Ultrasound and Anatomopathological Mammography Correlation in Yaounde. Journal of Radiology, 90, 1494.

https://doi.org/10.1016/S0221-0363(09)75848-2 